\title{
La logoterapia y sus claves para afrontar el sufrimiento
}

\author{
Logotherapy and its keys to coping with suffering
}

\author{
Ellisson Mike Andrade Dussán \\ Estudiante Programa de Psicología, Universidad Surcolombiana, Colombia \\ elian201166@hotmail.com
}

María Angélica Trujillo González Universidad Surcolombiana, Colombia angelicatrujillogonzalez@gmail.com

\section{Introducción}

El sufrimiento es un aspecto inherente a la naturaleza humana, algo que se quiere constantemente evitar, una condición, un estado, un sentimiento asociado comúnmente al dolor por lo que esto pueda generar de manera negativa en la experiencia humana. Nos enfrentamos en el transcurso de nuestras vidas a episodios vistos como desafortunados los cuales no deseamos experimentar y que en muchas ocasiones se tornan inevitables como por ejemplo, una enfermedad, la pérdida de un ser querido, dolor físico, humillaciones, pobreza, hambre, todo un abanico de situaciones que van desde el sufrimiento físico, psicológico y hasta de índole social. Una variedad de motivos para sentir en ocasiones que no hay más opciones para continuar, y es allí justo cuando se hace necesario contar con recursos personales que permitan hacerle frente de la mejor manera posible.

Pinedo (2014) plantea que el sufrimiento puede llevar a las personas a situaciones límite y esto puede tomar dos caras, por un lado la parte negativa percibida como un estancamiento $\mathrm{y}$ fracaso que genera incertidumbre, angustia y desesperación, incluso pérdida del sentido de vida. Y por otro lado, una cara positiva que nos puede llevar a la reflexión constante y empezar a ver las cosas de otro modo, del modo que convendría apaciguar el dolor y dar sentido a la existencia misma. Una especie de resolución subjetiva para salir de tal estancamiento dotando de sentido a la vida o la existencia propia humana.
Esta perspectiva sobre el sentido de vida que se puede lograr en situaciones adversas se corresponde con lo que aportó teóricamente y también su testimonio de vida, el psiquiatra Austriaco Viktor Frankl, quien es el fundador de la logoterapia "esa psicoterapia que se centra en el sentido de la vida así como en la búsqueda de ese sentido por el hombre" (Frankl, 2001:84). Una propuesta desarrollada y consolidada a partir de sus propias vivencias durante el tiempo que permaneció como prisionero en los campos de concentración nazis, las cuales narra a lo largo de su obra El Hombre en busca de Sentido. En palabras de García (2006) "El Dr. Viktor Frankl fue un hombre que sufrió y supo dar sentido a su sufrimiento a través de su creatividad teórica".

Es precisamente, a partir de la lectura de la obra mencionada, que nace el interés por la Logoterapia, surgiendo de allí la inspiración para escribir estas líneas en las que se busca resaltar y compartir con los lectores del presente ensayo aspectos importantes de la propuesta logoterapéutica, escritos a manera de "claves", las cuales representan puntos esenciales para comprender de manera sucinta el valor de la dimensión espiritual, el manejo de la tensión, la actitud positiva, la esperanza y encontrar el sentido a la experiencia de vida para afrontar el sufrimiento de la mejor manera posible. Frankl señala que: "el sentido potencial de la vida es incondicional: la vida tiene sentido, potencialmente, bajo todas las circunstancias, aún las más adversas" (Frankl, 1992: 72), de manera que la vida no pierde sentido ante el 
sufrimiento, por el contrario, la búsqueda de sentido se torna aun más relevante frente a condiciones difíciles.

\section{Claves para afrontar el sufrimiento}

\section{Descubrir el sentido a través del sufrimiento}

De acuerdo con la logoterapia, la búsqueda de sentido es la principal motivación humana (Frankl, 2004.121), motivación y búsqueda que se torna aun más relevante frente a condiciones dolosas, adversas y conflictivas, frente a las cuales experimentamos el sufrimiento, pero si logramos develar el sentido oculto tras ese sufrimiento podemos convertirlo en logro humano (Lukas, 2006:168), por lo tanto, el descubrimiento de sentido nos brinda una dirección hacia la cual orientar nuestros esfuerzos; nos hace ver con claridad las metas y propósitos vitales que debemos realizar a pesar de lo difícil que nos pueda resultar dicho empeño. De este modo, comprender que a pesar del sufrimiento aun se tiene una misión por cumplir, nos hace sentir necesarios e imprescindibles; nos lleva a que comprendamos la razón de ser de nuestra existencia y trascender el sufrimiento, ideas que obedecen a uno de los grandes supuestos teóricos planteados por Frankl:

A este aspecto de la autotrascendencia, el hecho fundamental de que el hombre apunte más allá de sí mismo hacia un sentido que primeramente debe descubrir y cuya plenitud debe lograr, suelo describirlo con el concepto de la teoría de la motivación como una voluntad de sentido (Frankl, 1994: 22).

Planteamiento respecto al cual Elizabeth Lukas, nos dice: "en esta voluntad se concentra la disposición de una persona para convertir en realidades posibilidades encontradas por ella en acciones con un máximo de sentido alcanzable" (Lukas, 2005:87), por lo tanto encontrar sentido al sufrimiento es la primera y fundamental clave de la logoterapia para afrontarlo, "Ningún sufrimiento puede derrotarnos si estamos preparados para encontrarle sentido" (Lukas, 2006: 98).

\section{Conservar la esperanza ante el sufrimiento}

En la propuesta logoterapéutica es fundamental el reconocimiento de la esperanza como un recurso interno que hace las veces de factor protector frente a las difíciles condiciones que se puedan estar viviendo, es esperar algo bueno a pesar del difícil panorama que se pueda estar presentando; un conocimiento que hace parte de la cultura popular, pero al ser manejado desde sus planteamientos teóricos ha llegado a ser empleado en numerosos estudios para demostrar su validez, como es el caso del trabajo realizado por García, Gallego, \& Pérez (2009) en el cual lograron demostrar que: "sentido de la vida y desesperanza mantienen una asociación significativa de tipo negativo, de manera que a mayor logro de sentido de la vida, niveles inferiores de desesperanza, y al contrario". Lo que se puede también interpretar como una relación significativa de tipo positivo entre el logro de sentido de la vida y la esperanza, de manera que a mayor logro de sentido de vida, niveles superiores de esperanza, esa que cotidianamente escuchamos decir es lo último que se pierde.

La esperanza es considerada un valor potencial que aumenta la posibilidad de dar continuidad a la existencia, es incluso un motor que nos motiva a responder de manera positiva ante un cambio repentino que nos ponga de frente al sufrimiento, de esta manera, "los valores que implican asumir una actitud esperanzadora y trascendente frente a la adversidad, al dolor, al sufrimiento inevitable o a la muerte, son los que mayor sentido pueden conferirle a la existencia humana" (Velásquez, 2009:102) de esta forma podemos reconocer la grandeza del ser humano capaz de encontrarle sentido al sufrimiento $y$ conservar la esperanza de un mejor porvenir a pesar de las condiciones desafortunadas que se puedan estar viviendo.

\section{Restaurar lo espiritual en el ser humano}

La logoterapia parte del supuesto que el hombre es un ser espiritual, ya que no está absolutamente condicionado biológica, social, y psicológicamente, puede elevarse por encima de 
esos condicionantes y trascenderlos llegando a su dimensión específica, su dimensión espiritual (Frankl, 2004:150). De tal forma le corresponde a la dimensión espiritual o noólogica como la denomina Frankl, la búsqueda humana de sentido, "la dimensión espiritual está habilitada para el interrogante del sentido y capacitada para responder con sentido" (Lukas, 2005:40), siendo esta dimensión la que le permite al ser humano ser verdaderamente libre y responsable de sus elecciones y acciones en respuestas a las condiciones que se estén presentando por adversas que sean. Respecto a esta dimensión se puede agregar que es: "el núcleo sano que permanece intacto ante la enfermedad y que facilita la expresión de manifestaciones saludables" (Martínez, 2007: 173) de allí la necesidad de permitir la expresión del desafiante poder del espíritu humano y sus recursos frente al sufrimiento.

Por lo tanto, los recursos de la dimensión noólogica deben ser movilizados para restituir y lograr el despliegue de lo espiritual en el ser humano, dentro de los principales recursos de esta dimensión encontramos: el autodistanciamiento el cual es considerado como la capacidad específicamente humana de poder observarse en situación, descentrándose de sí mismo, para lograr ampliar el horizonte de posibilidades en medio de las problemáticas dadas; y la autotrascendencia entendida como la aquella capacidad de percibir valores y sentidos más allá de sí mismo, encontrando en una causa, en el ser dados al bienestar de los otros, las razones suficientes para hallarle y realizar el sentido de vida (Martínez, 2007).

Manejar el nivel de tensión interior entre lo que es y lo que se debe llegar a ser

Al apuntar la práctica logoterapéutica a la confrontación con el sentido de la existencia, considera que el ser humano no busca evadir tensiones, sino manejarlas y orientarlas hacia la realización de valores, "Cierto que la búsqueda humana de sentido y de valores puede nacer de una tensión interior y no de un equilibrio interno. Ahora bien, precisamente esa tensión es un requisito indispensable de salud mental"
(Frankl, 2004:127) y tramitar cierto nivel de tensión interior entre lo que es y lo que debe llegar a ser, es fundamental para lograr cumplir con los propósitos hacia los cuales nos proyectamos. En este sentido, "La logoterapia mira hacia el futuro, es decir, al sentido y los valores que el paciente quiere realizar en el futuro, al aplicarla el paciente se enfrenta con el sentido de su propia vida", (Frankl, 2004:120) por lo tanto desde esta perspectiva nos vemos confrontados con la responsabilidad de actuar coherentemente con nuestros propósitos vitales y llevarlos a cabo a pesar de las difíciles condiciones por las que estemos atravesando; por supuesto, es preciso mencionar que cuando sufrimos esperamos que nos brinden consideración y consuelo, pero especialmente debemos mantenernos motivados para seguir luchando nuestros propósitos a pesar de la adversidad.

\section{Asumir con buena actitud el sufrimiento}

Mostrar una buena actitud frente a las difíciles condiciones que se estén viviendo es reflejo del proceso de crecimiento interior: logro de sentido, mantener la esperanza, restitución de lo espiritual, y capacidad de manejo de la tensión interior; recursos desarrollados a partir de la exigencia presentada por la experiencia de sufrimiento. En este caso la logoterapia nos habla de la realización de sentido a través de los valores de actitud, "lo que distingue los valores de actitud es que benefician a otros, y no necesariamente a la persona que está creando una nueva actitud" (Lukas, 2006:167) por lo tanto, nos permiten mostrar nuestra grandeza como seres humanos, ya que al afrontar un sufrimiento que se nos torna ineludible, nuestra meta y propósito a realizar consiste en brindar testimonio de vida, ejemplo y alivio a los seres queridos evitándoles el sufrimiento innecesario, "Por medio de una actitud correcta, el sufrimiento inevitable se cambia en un logro heroico y victorioso." (Frankl, 2001:98), en un testimonio de vida como el que le permitió a Frankl desarrollar su propuesta de tan gran valor para quienes atraviesan por situaciones desafortunadas y poder conocer sus planteamientos les posibilita vislumbrar una perspectiva esperanzadora a pesar de la adversidad. 


\section{Reflexiones finales}

Estas enseñanzas presentadas en forma de "claves" en realidad obedecen a una sola estructura teórica desarrollada por Frankl en la logoterapia, propuesta de la cual solo se tomaron algunos de sus grandes aportes. Así mismo estas "claves" son válidas tanto para afrontar el sufrimiento, como para hacer frente a las crisis y problemáticas de la vida cotidiana en las cuales también pueden desempeñar un papel importante.

Al contar con estas "claves", el verdadero reto consiste en llevarlas a la práctica, puesto que nos resulta muy difícil aceptar y afrontar el sufrimiento, por tanto, es muy factible que en primera instancia se den las respuestas opuestas a las claves planteadas: frustración de sentido, desesperanza, restricción de lo espiritual, dificultad para manejar la tensión interior, y en esta medida difícilmente puede reflejarse una buena actitud en ante el sufrimiento, lo cual es completamente comprensible requiriendo de un complejo proceso de crecimiento interior para lograr transformar en logro el sufrimiento.

Finalmente, conocer estas claves, nos brinda unas excelentes enseñanzas para cuando nos enfrentemos a situaciones adversas o debamos orientar a quien sufre hacia el logro de sentido, conservar la esperanza, restituir lo espiritual en su ser, manejar la tensión interior y como resultado de este proceso de crecimiento interior y despliegue de lo espiritual, no solo reflejar una buena actitud frente al sufrimiento, sino trascenderlo, dando testimonio de la grandeza del ser humano, en últimas dando sentido a la vida aún en las situaciones más adversas.

\section{Referencias}

Frankl, V. (1992). Teoría y terapia de las neurosis. Barcelona: Herder.
Frankl, V. (1994). La voluntad de Sentido. Barcelona: Herder.

Frankl, V. (2001). Psicoterapia y existencialismo. Barcelona: Herder.

Frankl, V. (2004). El Hombre en busca de Sentido. Barcelona: Herder.

García, J., Gallego, j., \& Pérez, E. (2009). Sentido de vida y desesperanza: un estudio empírico. Univ. Psychol., vol. 4: 447-454.

Lukas, E. (2005). Una vida fascinante. Buenos Aires: San Pablo.

Lukas, E. (2006). También tu sufrimiento tiene sentido. México: LAG.

García, E. (2006). Logoterapia para nuestra época. Revista de Especialidades MédicoQuirúrgicas, vol. 11, pp. 21-23. Instituto de Seguridad y Servicios Sociales de los Trabajadores del Estado México.

Martínez, E. (2007). Psicoterapia y Sentido de Vida. Bogotá: Herder.

Velásquez, L. (2009). Logoterapia con personas que experimentan dolor, sufrimiento y pérdida del sentido de la vida. CES Psicología, vol. 2, pp. 95-105 Universidad CES Medellín, Colombia.

Pinedo, I. (2014). Apropiación del sufrimiento y búsqueda de sentido. Tesis Psicológica, vol. 9, pp. 36-49. Fundación Universitaria Los Libertadores. Bogotá, Colombia. 